\title{
Knowledge of HIV status prior to a community HIV counseling and testing intervention in a rural district of south Africa: results of a community based survey
}

Hanani Tabana ${ }^{1,3^{*}}$, Tanya Doherty ${ }^{1,2}$, Sonja Swanevelder ${ }^{1}$, Carl Lombard ${ }^{1}$, Debra Jackson², Wanga Zembe ${ }^{1}$ and Reshma Naik 1,4

\begin{abstract}
Background: The low uptake of facility-based HIV counseling and testing (HCT) in South Africa, particularly amongst men and youth has hindered attempts to increase access to effective treatment and prevention strategies. Many barriers to HIV testing have been described including long waiting times, transport to reach facilities, fear of lack of confidentiality and health systems factors such as stock outs of HIV test kits. The aim of this study was to undertake a community survey to determine rates of HCT in a rural area in order to plan a community intervention.

Methods: A community-based survey was undertaken in 16 communities in Sisonke district, KwaZulu-Natal between September and November 2008. A total of 5821 individuals participated in the survey of which 66\% were females. Gender specific mixed effects logistic regression models were used to describe differences in socioeconomic characteristics, and their association with HIV testing histories.

Results: Overall 1833 (32\%) individuals in this rural area knew their HIV status. Prior testing was higher amongst women (39\%) than amongst men (17\%). Older men (> 24 years) were more likely to report having tested for HIV previously, with the highest likelihood (adjusted $\mathrm{OR}=4.02 ; 95 \% \mathrm{Cl}$ : 2.71-5.99) among men in age group, 35-49 years. For women, age group 25-34 years had the highest likelihood of having been previously tested (adjusted OR $=1.30 ; 95 \% \mathrm{Cl}: 1.05-1.66)$. Being currently pregnant (adjusted OR 3.31; 95\% Cl: 2.29 - 4.78) or having a child under five (adjusted OR 7.00; 95\% Cl: 5.84 - 8.39) were also associated with prior HIV testing amongst women.

Conclusions: Overall, knowledge of HIV status in this rural sub-district is low. The relatively higher uptake of HIV testing among women is encouraging as it shows that PMTCT services are well functioning. However, these data suggest that there is an urgent need for scaling up HIV testing services in rural communities specifically targeting men and youth.
\end{abstract}

\section{Background}

HIV counseling and testing (HCT) has become an integral part of HIV prevention in sub-Saharan Africa [1] and an entry point to care, treatment and support for people living with HIV/AIDS. The low uptake of facility-based HCT in South Africa, particularly amongst

\footnotetext{
* Correspondence: hanani.tabana@mrc.ac.za

'Medical Research Council, Francie van Zyl Drive, Parrow, Cape Town, South Africa

Full list of author information is available at the end of the article
}

young adults, has hindered attempts to increase access to effective treatment and prevention strategies. Many barriers to HIV testing have been described including social and economic barriers, and health systems factors [2]. Several strategies to increase uptake of HCT among sub-Saharan populations have been recommended [2] such as; mobile or community HCT, home-based testing, provider initiated HCT and routine (or opt-out) testing as part of medical care. These strategies have had varying degrees of success and their impact on the
C Biomed Central

(c) 2012 Tabana et al; licensee BioMed Central Ltd. This is an Open Access article distributed under the terms of the Creative Commons Attribution License (http://creativecommons.org/licenses/by/2.0), which permits unrestricted use, distribution, and reproduction in any medium, provided the original work is properly cited. 
poorest rural populations may be limited. Enrollment of infected individuals into care therefore continues to be hampered by the low uptake of HCT [3] even in settings where HCT services are available [4-7].

South Africa currently has an overall national HIV prevalence of $17.8 \%$, while the antenatal clinic (ANC) prevalence in women aged $15-49$ years was $30.2 \%$ in 2010 [8]. These high HIV prevalence rates warrant interventions to increase the optimal use of HCT services. In an effort to address the high HIV prevalence, the South African government launched a national HCT campaign in 2010, targeting 15 million South Africans to test for HIV by June 2011 [9].

In many settings, HIV test uptake has been correlated with factors such as gender, education levels, geographical location, and number of sexual partners, amongst others $[7,10]$. A review on HCT uptake in sub-Saharan African countries using country level demographic and health survey (DHS) data reported that, in 26 countries in sub-Saharan Africa, $10 \%$ of women with no schooling reported having tested but throughout primary, secondary and higher education categories, testing uptake increased from $10 \%$ to $15 \%, 23 \%$ and $44 \%$ respectively. The review also reported that the findings based on the DHS wealth index showed that there was an increase in the likelihood of having had an HIV test with percentages ranging from $10 \%$ (poorest quintile) to $25 \%$ (wealthiest quintile). Testers were wealthier, more educated and less likely to be married [10].

In another study by Helleringer et al. 2009, reporting ever having tested for HIV at a health facility was correlated with; older age, increased number of schooling years, and having had multiple sexual partners over 3 years prior to the survey. During this study, when respondents were asked, they indicated distance to testing centre, lack of confidentiality in health facilities, and fear of diagnosis as reasons for not accessing services [3].

In South Africa, Venkatesh et al. 2011 [11] reported findings on characteristics of HIV 'testers' in a crosssectional survey involving 1539 men and 1877 women in an urban township. Sixty eight percent of women reported prior testing compared to $29 \%$ of men. In this study, men and women who had heard about ARV therapy were more likely to report HIV testing, and repeated testing. Men who had more than 12 years of education and who were of high economic status, and women who were married and were of low economic status, and who had children under their care were more likely to have tested previously.

There is limited literature on HCT uptake in rural populations in South Africa. This paper reports findings from a baseline survey to ascertain prior HIV testing and predictors of knowledge of HIV status amongst inhabitants of the rural UMzimkhulu sub-district of KwaZulu-Natal, the province with the highest HIV prevalence in South Africa, prior to the implementation of a home-based HCT intervention trial.

\section{Methods}

\section{Study design}

A community-based survey was undertaken in 16 communities in Sisonke district, KwaZulu-Natal between September and November 2008. The community survey was implemented in one sub-district, UMzimkhulu within Sisonke, one of the poorest rural areas in South Africa, where $77 \%$ of households live below the poverty line [12]. Maps showing population numbers based on the Statistics South Africa (Stats SA) census were used to demarcate clusters with approximately 150 households in each. The purpose of the survey was to collect baseline information on knowledge of HIV status prior to implementation of a home based HCT intervention trial known as the Good Start study (ISRCTN31271935).

\section{Data collection}

One data collector was assigned to each of the 16 clusters. She visited all households in a systematic manner and enumerated them using a household listing form obtained from Statistics South Africa. Upon reaching a household, all members of the household aged 18 years and older were asked for verbal consent to be interviewed. Data was collected using interviewer administered questionnaires uploaded on cell phones and transmitted via GPRS into a central database.

Interviews took place in a private place in the participant's home. The interviews were administered in Zulu or Xhosa, the local languages in the study area. Questions in the interviews included demographic characteristics of study participants (age, gender, and education), socio-economic status indicators (infrastructure and individual assets owned) and previous HIV testing history. Ethical approval for the survey was obtained from the University of the Western Cape research ethics committee.

\section{Statistical analyses}

The primary outcome was a binary variable, "previous HIV testing" and "No previous HIV testing". All data analysis was conducted using STATA version 10 software (StataCorp LP, USA). Univariate and multivariate logistic regression was used to investigate factors associated with previous HIV testing. Gender specific models were fitted and included socio-demographic characteristics (age, educational attainment, socio-economic status) infant deaths in households, current pregnancy, household births, and children under 5 in the household. The dependency structure of the data 
relating to clusters and households was taken into account by including random effects in the models. All variables that were statistically significant in univariate analyses were included in multivariate analysis. In case of collinearity, one of the variables was dropped from the model. Prior to logistic regression model building, we conducted a TREE regression analysis which indicated major interactions between 'gender' and some socio-demographic variables. Based on these results and the fact that some variables were only applicable to women; we computed gender specific mixed effects logistic regression models and report odds ratios and 95\% confidence intervals (CI). A post estimation test, "Wald test" for simple and composite linear hypotheses about the parameters of a fitted model was computed to compare levels of multilevel variables.

\section{Results}

\section{Characteristics of study participants}

Three thousand and forty nine households were approached and $86 \%$ of these were included in the survey. Very few households refused to take part $(<1 \%)$ and the most common reason (93\%) for not including a household in the survey was that the owners were living and working in an urban area and the house was vacant. Out of the 2651 included households, a total of 5821 individuals were interviewed of which 3863 (66\%) were females. Sixty-nine percent of the sample used rivers or a communal tap for drinking water and 63\% used wood for cooking fuel. The mean age of men was 42 years (range 18-100 years) and the mean age of women was 39 years (range 18-95 years). Seventy four percent of men and women had some primary schooling or had completed primary school.

\section{History of HIV testing}

Of the total sample, 1833 (32\%) people reported having tested for HIV previously. Of those who had tested previously, 82\% were women. Among men, only 17\% (323/ 1958) had previously tested for HIV, while for women this rate was $39 \%(1510 / 3863)$. Encouragingly $75 \%$ of women who reported being pregnant at the time of the survey had tested for HIV. The most common place for people to test (77\%) was clinics and hospitals. Figure 1 shows the distribution of location where HIV testing was done by gender.

\section{Predictors of prior HIV testing}

Tables 1 and 2 show univariate and multivariate analysis of socio-demographic characteristics associated with previous HIV testing among men and women respectively. Predictors of testing varied by gender and therefore are presented separately. In multivariate analysis, older men (> 24 years) were more likely to report having tested for HIV previously (compared with 18-24 years), with the highest likelihood (adjusted OR 4.02; 95\% CI: 2.71-5.99) among men in age group 35-49 years (Table 1). For women, age group 25-34 years (compared with 18-24 years) had the highest likelihood of having been previously tested (adjusted OR 1.3; 95\% CI: 1.051.66). Women older than 50 years were less likely (adjusted OR 0.39; 95\% CI: 0.31-0.51) to report ever testing for HIV previously (Table 2). The post estimation test indicated that there were significant $(\mathrm{P}<0.05)$ differences between successive age groups 25-34 and 3549 years among women, and also between age groups 25-34 and 35-49 years among men.

Education was not associated with testing in men but was associated with testing in women with education levels, "completed high school" and "completed tertiary" having adjusted OR 2.03; 95\% CI: 1.15-2.87 and adjusted OR 2.99 ; $95 \%$ CI: $1.68-5.33$ respectively compared to no education.

Socio-economic factors were associated with testing history for men and women. Among men using electricity as primary cooking fuel compared to those using wood (adjusted OR 1.42; 95\% CI: 1.04-1.93) was positively associated with testing as well as having piped water inside the house or yard compared with all other sources of water (adjusted OR 1.66; 95\% CI: 1.14-2.40) (Table 1). In women neither drinking water source nor cooking fuel was predictive of prior HIV testing (Table 2 ). However, women with a cell phone were more likely to have tested (OR 1.49; 95\% CI: 1.22-1.81).

For women, current pregnancy (adjusted OR 3.31; 95\% CI: 2.29-4.78) and having a child less than 5 years of age (adjusted OR 7.00; 95\% CI: 5.84- 8.39) were strongly associated with previous HIV testing. Giving birth in the past year was also predictive of prior HIV testing (adjusted OR 2.54; 95\% CI: 2.01-3.19).

\section{Discussion}

This large community based survey in rural South Africa has found that only $32 \%$ of adults had ever been tested for HIV previously. This is concerning, especially in the province with the highest HIV prevalence in South Africa [8]. The most recent National HIV, behavior and health survey in South Africa found that in KwaZulu-Natal province, only $24 \%$ of adults in the age group 15-49 years had tested for HIV in the past year [13]. We found an even lower rate of HIV testing (17\%) amongst men which could be attributable to the fact that in this rural area with limited access to non clinical HIV testing services, men are unlikely to voluntarily test for HIV unless they are ill and attend health care services. Another possible explanation could be due to the common phenomenon of 'proxy' testing among men which has been reported in South Africa, where men 


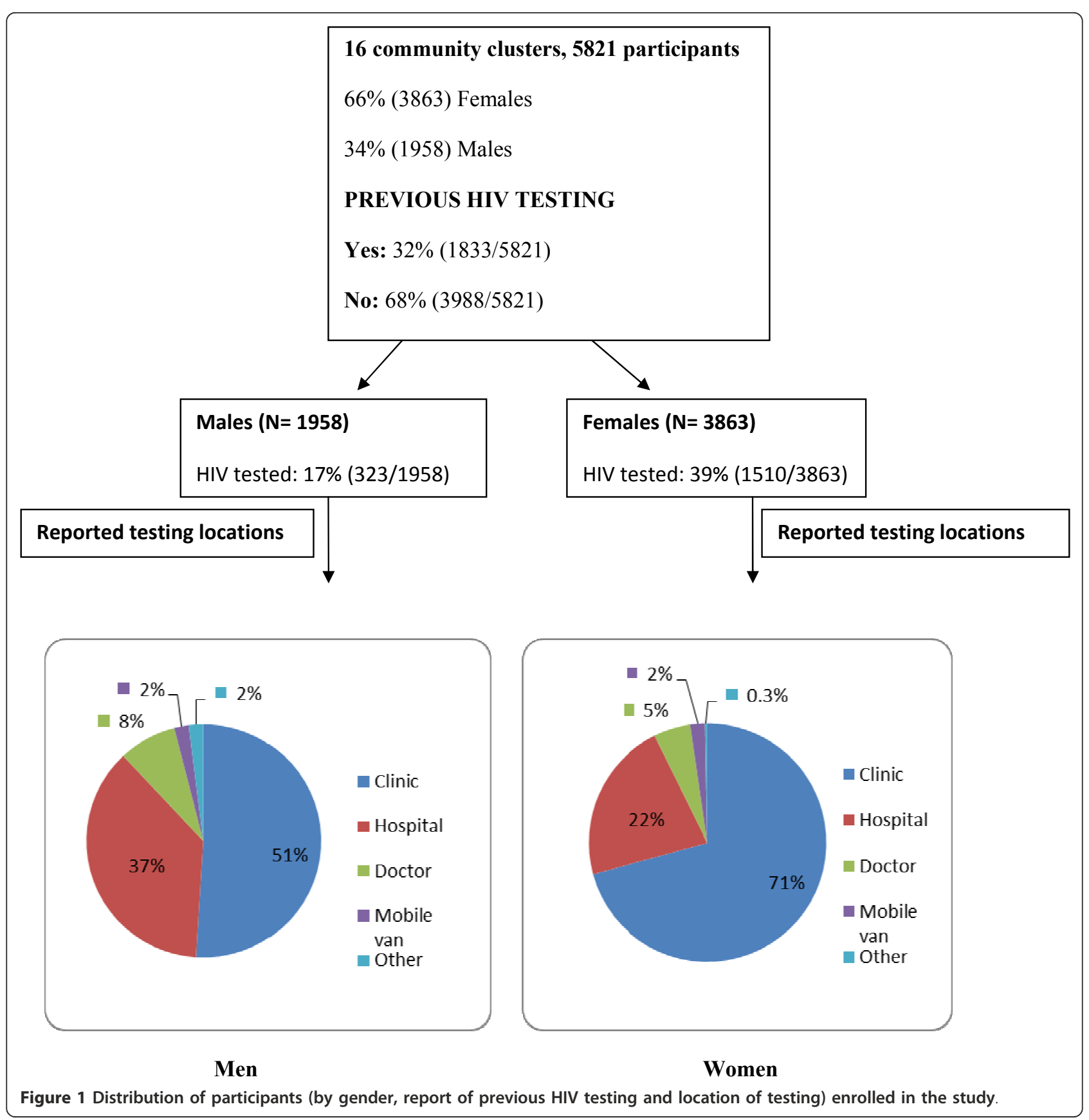

entrust testing to their partners assuming that their status would be the same as that of their partners [14].

For many years, primary health clinics and hospitals have provided the only access to HCT in South Africa and other high HIV prevalence settings hence the majority of participants who reported prior HIV testing had tested at a clinic or hospital. Given the low rate of testing under these circumstances the shift to non-clinical venues for HCT [2] is critical to increase population level coverage of HIV testing.
Our findings show that the most significant predictor of previous HIV testing was age group. Among men, those 35-49 years, and among women, those 25-34 years were more likely to test compared to those 18-24 years. Women in the age group 25-34 years are mostly in the child bearing age, hence it is expected that these women may have been tested in the antenatal clinic. Women of reproductive age are more likely to come into frequent contact with the health system where they are offered HCT services. However, among women, being older 
Table 1 Univariate and multivariate analysis of socio-demographic characteristics associated with previous HIV testing among MEN in rural Sisonke district, South Africa $(n=1958)$

\begin{tabular}{|c|c|c|c|}
\hline Characteristic & Proportion reporting & & \\
\hline & previous HIV testing & Crude OR & Adjusted OR \\
\hline & Yes, n/N (\%) & OR $(95 \% \mathrm{Cl})$ & OR $(95 \% \mathrm{Cl})$ \\
\hline \multicolumn{4}{|l|}{ Age group, yrs } \\
\hline $18-24$ & $42 / 570(7.4)$ & 1.00 & \\
\hline $25-34$ & $81 / 370(21.9)$ & $3.52(2.59-4.79)$ & $3.44(2.30-5.18)$ \\
\hline $35-49$ & $102 / 430(23.7)$ & $3.91(2.94-5.20)$ & $4.02(2.71-5.99)$ \\
\hline $50+$ & $98 / 588(16.7)$ & $2.51(1.73-3.65)$ & $2.62(1.76-3.90)$ \\
\hline \multicolumn{4}{|l|}{ Education Level } \\
\hline None & 21/135 (15.6) & 1.00 & \\
\hline Primary school & 234/1442 (16.2) & $1.05(0.73-1.51)$ & $1.22(0.74-2.03)$ \\
\hline Completed High school & $48 / 289(16.6)$ & $1.08(0.61-1.91)$ & $1.28(0.69-2.36)$ \\
\hline Tertiary & 20/92 (21.7) & $1.51(0.86-2.65)$ & $1.17(0.58-2.39)$ \\
\hline \multicolumn{4}{|l|}{ Drinking water source } \\
\hline All other sources & 253/1647 (15.4) & 1.00 & \\
\hline Piped (inside house and yard) & $70 / 311(22.5)$ & $1.60(1.09-2.34)$ & $1.66(1.14-2.4)$ \\
\hline \multicolumn{4}{|l|}{ Cooking fuel } \\
\hline Wood & 174/1195 (14.6) & 1.00 & \\
\hline Paraffin/Kerosene/Gas & $41 / 215(19.1)$ & $1.38(0.69-2.75)$ & $1.18(0.77-1.78)$ \\
\hline Electricity & 108/548 (19.7) & $1.44(0.94-2.21)$ & $1.42(1.04-1.93)$ \\
\hline \multicolumn{4}{|l|}{ Infant deaths in past year } \\
\hline No & $279 / 1740(16.0)$ & 1.00 & \\
\hline Yes & $44 / 218(20.2)$ & $1.32(0.92-1.91)$ & $1.25(0.86-1.80)$ \\
\hline \multicolumn{4}{|l|}{ Infant births in past year } \\
\hline No & $128 / 970(13.2)$ & 1.00 & \\
\hline Yes & $57 / 340(16.8)$ & $1.32(0.89-1.96)$ & \\
\hline \multicolumn{4}{|l|}{ No. of people living together } \\
\hline$<=2$ & 134/738 (18.2) & 1.00 & \\
\hline$>2$ & $189 / 1220(15.5)$ & $0.83(0.62-1.09)$ & \\
\hline \multicolumn{4}{|l|}{ Household wall material } \\
\hline Other & $10 / 69(14.5)$ & 1.00 & \\
\hline Mud/wood/grass & 107/600 (17.8) & $1.28(0.81-2.03)$ & \\
\hline Brick/cement/corrugated iron & 206/1289 (16.0) & $1.12(0.63-1.98)$ & \\
\hline \multicolumn{4}{|l|}{ Refrigerator } \\
\hline No & 181/1097 (16.5) & 1.00 & \\
\hline Yes & $142 / 861(16.5)$ & $0.99(0.82-1.22)$ & \\
\hline \multicolumn{4}{|l|}{ Radio } \\
\hline No & 80/488 (16.4) & 1.00 & \\
\hline Yes & $243 / 1470(16.5)$ & $1.01(0.77-1.33)$ & \\
\hline \multicolumn{4}{|l|}{ Television } \\
\hline No & 152/853 (17.8) & 1.00 & \\
\hline Yes & $171 / 1105(15.5)$ & $0.84(0.63-1.13)$ & \\
\hline \multicolumn{4}{|l|}{ Cell phone } \\
\hline No & $61 / 374(16.3)$ & 1.00 & \\
\hline Yes & 262/1584 (16.5) & $1.02(0.68-1.51)$ & \\
\hline \multicolumn{4}{|l|}{ Stove } \\
\hline No & $80 / 456(17.5)$ & 1.00 & \\
\hline
\end{tabular}


Table 1 Univariate and multivariate analysis of socio-demographic characteristics associated with previous HIV testing among MEN in rural Sisonke district, South Africa $(n=1958)$ (Continued)

\begin{tabular}{lll}
\hline Yes & $243 / 1584(16.2)$ & $\mathbf{0 . 9 1 ( 0 . 6 6 - 1 . 2 4 )}$ \\
\hline Cupboard & & \\
\hline No & $97 / 527(18.4)$ & 1.00 \\
\hline Yes & $226 / 1431(15.8)$ & $\mathbf{0 . 8 3}(\mathbf{0 . 6 1 - 1 . 1 4 )}$ \\
\hline
\end{tabular}

Table 2 Univariate and multivariate analysis of socio-demographic characteristics associated with previous HIV testing among WOMEN in rural Sisonke district, South Africa

\begin{tabular}{|c|c|c|c|}
\hline Characteristic & Proportion reporting & & \\
\hline & previous HIV testing & Crude OR & Adjusted OR \\
\hline & Yes, n/N (\%) & OR $(95 \% \mathrm{Cl})$ & OR $(95 \% \mathrm{Cl})$ \\
\hline \multicolumn{4}{|l|}{ Age group, yrs } \\
\hline $18-24$ & $488 / 905(54.0)$ & 1.00 & \\
\hline $25-34$ & $473 / 735(64.4)$ & $1.54(1.27-1.88)$ & $1.32(1.05-1.66)$ \\
\hline $35-49$ & $368 / 898(41.0)$ & $0.59(0.47-0.75)$ & $1.00(0.80-1.25)$ \\
\hline $50+$ & $181 / 1325$ (13.7) & $0.14(0.10-0.18)$ & $0.39(0.31-0.51)$ \\
\hline None & 28/233 (12.0) & 1.00 & \\
\hline Primary school & 1082/2846 (38.0) & $4.49(2.41-8.37)$ & $1.82(1.16-2.87)$ \\
\hline Completed High school & $319 / 608(52.5)$ & $8.08(4.57-14.29)$ & $2.03(1.23-3.36)$ \\
\hline Tertiary & $81 / 174(46.6)$ & $6.38(3.62-11.24)$ & $2.99(1.68-5.33)$ \\
\hline All other sources & 1334/3367 (39.6) & 1.00 & \\
\hline Piped (inside house and yard) & 176/496 (35.5) & $0.83(0.69-1.02)$ & $0.88(0.65-1.18)$ \\
\hline$<=2$ & $784 / 1943(40.4)$ & & \\
\hline$>2$ & $726 / 1920(38.0)$ & & \\
\hline Wood & $974 / 2490(39.1)$ & 1.00 & \\
\hline Paraffin/Kerosene/Gas & $149 / 400(37.3)$ & $0.92(0.69-1.23)$ & $0.96(0.72-1.28)$ \\
\hline Electricity & $387 / 973(39.8)$ & $1.03(0.78-1.36)$ & $1.05(0.85-1.31)$ \\
\hline \multicolumn{4}{|l|}{ No } \\
\hline Yes & 1317/3394 (38.8) & & \\
\hline $193 / 469(41.2)$ & 1.00 & & \\
\hline $0.91(0.68-1.21)$ & $1.14(0.89-1.44)$ & & \\
\hline \multicolumn{4}{|l|}{ Child Under 5} \\
\hline No & $588 / 2651(22.2)$ & 1.00 & \\
\hline Yes & $922 / 1212(76.1)$ & $11.15(7.23-17.20)$ & $7.00(5.84-8.39)$ \\
\hline \multicolumn{4}{|l|}{ Currently pregnant } \\
\hline No & $1358 / 3660(37.1)$ & 1.00 & \\
\hline Yes & 152/203 (74.9) & $5.05(2.91-8.76)$ & $3.31(2.29-4.78)$ \\
\hline \multicolumn{4}{|l|}{ Infant births in past year } \\
\hline No & $575 / 1856(30.9)$ & 1.00 & \\
\hline Yes & 403/757 (53.2) & $2.54(2.01-3.19)$ & \\
\hline No & 942/2303 (40.9) & 1.00 & \\
\hline \multicolumn{4}{|l|}{ Yes } \\
\hline Radio & $568 / 1560(36.4)$ & $0.83(0.69-0.99)$ & \\
\hline No & 423/967 (43.7) & 1.00 & \\
\hline Yes & 1087/2896 (37.5) & $0.77(0.65-0.92)$ & \\
\hline Yes & 772/2039 (37.9) & $0.89(0.74-1.08)$ & \\
\hline
\end{tabular}


Table 2 Univariate and multivariate analysis of socio-demographic characteristics associated with previous HIV testing among WOMEN in rural Sisonke district, South Africa (Continued)

\begin{tabular}{lcc}
\hline Cell phone & & \\
\hline Yes & $1284 / 3149(40.8)$ & $\mathbf{1 . 4 9 ( \mathbf { 1 . 2 2 } - \mathbf { 1 . 8 1 } )}$ \\
\hline Stove & $1155 / 2870(38.9)$ & $\mathbf{0 . 9 6}(\mathbf{0 . 8 1 - 1 . 1 6 )}$ \\
\hline Yes & & \\
\hline Cupboard & $1093 / 2846(38.4)$ & $\mathbf{0 . 8 9}(\mathbf{0 . 7 3 - 1 . 1 1 )}$ \\
\hline
\end{tabular}

(age groups $50+$ years compared to age group $18-24$ years) was associated with a relatively lower likelihood to test. These findings of less testing in older age groups is consistent with the literature [15-17] and needs further exploration as high HIV prevalence rates have been previously reported in this age group [16,17]. A possible explanation for less testing amongst older women could be that older people are often in stable relationships and have a lower HIV risk perception. Furthermore, as compared with the present day, HIV testing of pregnant women in South Africa was not routine prior to 2001 when these older women would have been in their child bearing years.

Previous surveys in South Africa have reported risky sexual behaviours among young people, between the ages $15-24$ years $[13,18,19]$. Therefore the finding of low levels of testing amongst young men is concerning and strategies specifically targeted at this group are urgently needed.

We found inconsistencies across gender for sociodemographic factors associated with HIV testing such as education, and infrastructure. Higher education was associated with testing in women but not in men. Higher education level is consistently seen in the literature to be associated with HIV testing $[7,10,11,20]$ though there have been conflicting results in other African settings, where having higher education was associated with a lower likelihood to undergo HCT [21]. Furthermore, we found men who had electricity and piped water to have a greater likelihood to have tested but these factors were not associated with testing in women. We used factors like electricity and piped water as a proxy for socio-economic status, and these findings may suggest that being of higher socio-economic status, better enabled men to test, whereas most women might have had to test at some point in their lifetimes during pregnancy regardless of socio-economic standing.

It is quite encouraging that current pregnancy and having a child under 5 was highly predictive of prior testing among women and this indicates that prevention of mother to child transmission of HIV (PMTCT) services are working well. HIV testing amongst antenatal clients in South Africa has increased from 49\% in 2004 to an average of $100 \%$ across all districts in the country in 2010/2011 [22]. However, the PMTCT programme is clearly not involving men, as a birth in the last year was not associated with HIV testing in men. Future HIV testing strategies should include scale up of couple counseling and testing in antenatal care settings as well as home-based couples testing to reach more men, especially those in the reproductive age. Furthermore in rural female dominated settings similar to the current study setting, where men largely work in the cities and are not at home for most of the year, interventions need to operate over holidays to reach these men.

The greatest strength of this study is that it was a large community wide survey with a high participation rate in a hard to reach rural area. However, there are some limitations to mention. We did not ask the participants why they tested or did not test and are thus unable to understand the underlying motivations to test or avoid testing in this specific population. It would also have been valuable to ask participants how recently they had tested since this would have indicated whether individuals are testing regularly according to the national guidelines. Since people may have tested several years prior to the survey, recall bias regarding place of testing is possible. Further research is needed, possibly qualitative, to explore motivations for testing or not testing in rural populations.

\section{Conclusion}

This study has shown low knowledge of HIV status, especially amongst men, in a poor rural area of South Africa. There is an urgent need to scale up HIV testing services in rural areas using community based approaches specifically targeting young men in order to increase access to HIV care and treatment and to promote safer sexual behavior amongst this high risk group.

\section{Acknowledgements}

We thank all the study participants, village leaders, data collectors, Sisonke District Department of Health and field supervisors. The study received financial support from the Medical Research Council of South Africa.

\section{Author details}

${ }^{1}$ Medical Research Council, Francie van Zyl Drive, Parrow, Cape Town, South Africa. ${ }^{2}$ University of the Western Cape, Modderdam Road, Bellville, Cape 
Town, South Africa. ${ }^{3}$ Division of Global Health (IHCAR), Department of Public Health Sciences, Karolinska Institutet, Nobels vag 9 5-171 77, Stockholm, Sweden. ${ }^{4}$ School of Public Health, Boston University, 715 Albany Street, Boston 02118, MA, USA.

\section{Authors' contributions}

$H T, T D, D J, W Z$ and RN planned and wrote the paper. SS and $C L$ were study statisticians. DJ, TD and HT contributed to manuscript design and content. $H T, W Z$, and RN had particular responsibility for study implementation. HT, RN and WZ were active with data management and analytic content. TD and DJ were principal investigators and planned the study design, oversaw implementation and worked on analytic content. All authors read and contributed towards the final draft. All authors read and approved the final manuscript.

\section{Competing interests}

The authors declare that they have no competing interests.

Received: 29 December 2011 Accepted: 29 March 2012

Published: 29 March 2012

\section{References}

1. De Cock KM, Marum E, Mbori-Ngacha D: A serostatus-based approach to HIV/AIDS prevention and care in Africa. Lancet 2003, 362(9398):1847-1849.

2. Matovu JKB, Makumbi FE: Expanding access to voluntary HIV counselling and testing in sub-Saharan Africa: alternative approaches for improving uptake, 2001-2007. Trop Med Int Health 2007, 12(11):1315-1322.

3. Helleringer $\mathrm{S}$, Kohler $\mathrm{H}$, Frimpong JA, Mkandawire J: Increasing Uptake of HIV Testing and Counseling Among the Poorest in Sub-Saharan Countries Through Home-based service provision. J Acquir Immune Defic Syndr 2009, 51(2):185-193.

4. Obermeyer CM, Osborn M: The utilization of testing and counseling for HIV: a review of the social and behavioral evidence. Am J Public Health 2007, 97(10):1762-1774.

5. Fylkesnes K, Haworth A, Rosensvard C, Kwapa PM: HIV counselling and testing: overemphasizing high acceptance rates a threat to confidentiality and the right not to know. AIDS 1999, 13(17):2469-2474.

6. Ma W, Detels R, Feng Y, Wu Z, Shen L, Li Y, et al: Acceptance of and barriers to voluntary HIV counselling and testing among adults in Guizhou province, China. AIDS 2007, 21:S129-135.

7. Mutale W, Michelo C, Jürgensen M, Fylkesnes Knut: Home-based voluntary HIV counselling and testing found highly acceptable and to reduce inequalities. BMC Public Health 2010, 10(347):1-7.

8. National Department of Health: National Antenatal Sentinel HIV and Syphilis Prevalence Survey in South Africa, 2010 Pretoria: Department of Health; 2011.

9. UNAIDS: UNAIDS Executive Director joins President Zuma to launch national HIV counselling and testing drive in South Africa. 2010 [http:// www.unaids.org/en/KnowledgeCentre/Resources/FeatureStories/archive/ 2010/20100426_MS_SA.asp], Accessed August 24, 2010.

10. Weinreb A, Stecklov G: Social inequality and HIV-testing: Comparing home- and clinic-based testing in rural Malawi. Demographic Res 2009, 21:627-646.

11. Venkatesh KK, Madiba P, Bruyn GD, Lurie MN, Coates TJ, Gray GE: Who Gets Tested for HIV in a South African Urban Township? Implications for Test and Treat and Gender-Based Prevention Interventions. J Acquir Immune Defic Syndr 2011, 56:151-165.

12. UMzimkhulu Local Municipality: Integrated Development plan for 2009/ 2010 financial year. 2010.

13. Human Sciences Research Council: South African National HIV Prevalence, Incidence, Behavior, and Communication Survey, 2008 Cape Town, South Africa: Human Sciences Research Council; 2009.

14. Mindrya D, Mamanb S, Chirowodzac A, Muravhad T, Rooyenc H, Coatesa T: Looking to the future: South African men and women negotiating HIV risk and relationship intimacy. Cult Health Sex 2011, 13(5):589-602.

15. Sekandi JN, Sempeera H, List L, Mugerwa MA, Asiimwe S, Yin X, Whalen CC: High acceptance of home-based HIV counseling and testing in an urban community setting in Uganda. BMC Public Health 2011, 11(730):1-8.

16. Negin J, Cumming RG: HIV infection in older adults in sub-Saharan Africa: extrapolating prevalence from existing data. Bull World Health Organ 2010, 88(11):847-853.
17. Negin J, Wariero J, Cumming RG, Mutuo P, Pronyk PM: High rates of AIDSrelated mortality among older adults in rural Kenya. J Acquir Immune Defic Syndr 2010, 55(2):239-244.

18. Shisana O, Rehle T, Simbayi O, Parker W, Zuma K, Bhana A: South African National HIV prevalence, HIV incidence, Behaviour and Communication Survey 2005. Cape Town; 2005.

19. Pettifor $A E$, Rees HV, Steffenson A: HIV and sexual risk behaviour among young South Africans: a national survey of 15-24 year olds. Johannesburg: Reproductive Health Research Unit, University of the Witwatersrand. 2004.

20. Sherr L, Lopman B, Kakowa M, Dube S, Chawira G, Nyamukapa C, Oberzaucher N, Cremin I, Gregson S: Voluntary counselling and testing: uptake, impact on sexual behaviour, and HIV incidence in a rural Zimbabwean cohort. AIDS 2007, 21(7):851-860.

21. Matovu JK, Gray RH, Makumbi F, Wawer MJ, Serwadda D, Kigozi G, Sewankambo NK, Nalugoda F: Voluntary HIV counseling and testing acceptance, sexual risk behavior and HIV incidence in Rakai, UgandaAIDS. AIDS 2005, 19(5):503-511.

22. Doherty T: PMTCT Indicators. In District Health Barometer 2010/2011. Edited by: Day C. Durban: Health Systems Trust; 2011:

\section{Pre-publication history}

The pre-publication history for this paper can be accessed here: http://www.biomedcentral.com/1471-2334/12/73/prepub

\section{doi:10.1186/1471-2334-12-73}

Cite this article as: Tabana et al: Knowledge of HIV status prior to a community HIV counseling and testing intervention in a rural district of south Africa: results of a community based survey. BMC Infectious Diseases 2012 12:73.

\section{Submit your next manuscript to BioMed Central and take full advantage of:}

- Convenient online submission

- Thorough peer review

- No space constraints or color figure charges

- Immediate publication on acceptance

- Inclusion in PubMed, CAS, Scopus and Google Scholar

- Research which is freely available for redistribution

Submit your manuscript at www.biomedcentral.com/submit
Ciomed Central 